\title{
Recruitment and Baseline Characteristics of Participants in the Social, Emotional, and Economic Empowerment Through Knowledge of Group Support Psychotherapy Study (SEEK-GSP): Cluster Randomized Controlled Trial
}

Etheldreda Nakimuli-Mpungu ${ }^{1}$, MMED(Psych), PhD; Seggane Musisi ${ }^{1}$, FRCPC; Kizito Wamala ${ }^{2}$, MSc; James Okello ${ }^{3}$, MMED(Psych), PhD; Sheila Ndyanabangi ${ }^{4 \dagger}, \mathrm{MBChB}, \mathrm{MPH}$; Josephine Birungi ${ }^{5}$, MBChB; Mastula Nanfuka ${ }^{5}, \mathrm{MBChB}$; Michael Etukoit ${ }^{5}, \mathrm{MBChB}$; Ramin Mojtabai ${ }^{6}, \mathrm{MD}$, PhD; Jean Nachega ${ }^{7,8,910}, \mathrm{MD}, \mathrm{PhD}$; Ofir Harari ${ }^{11}$, PhD; Edward Mills $^{12}, \mathrm{PhD}$

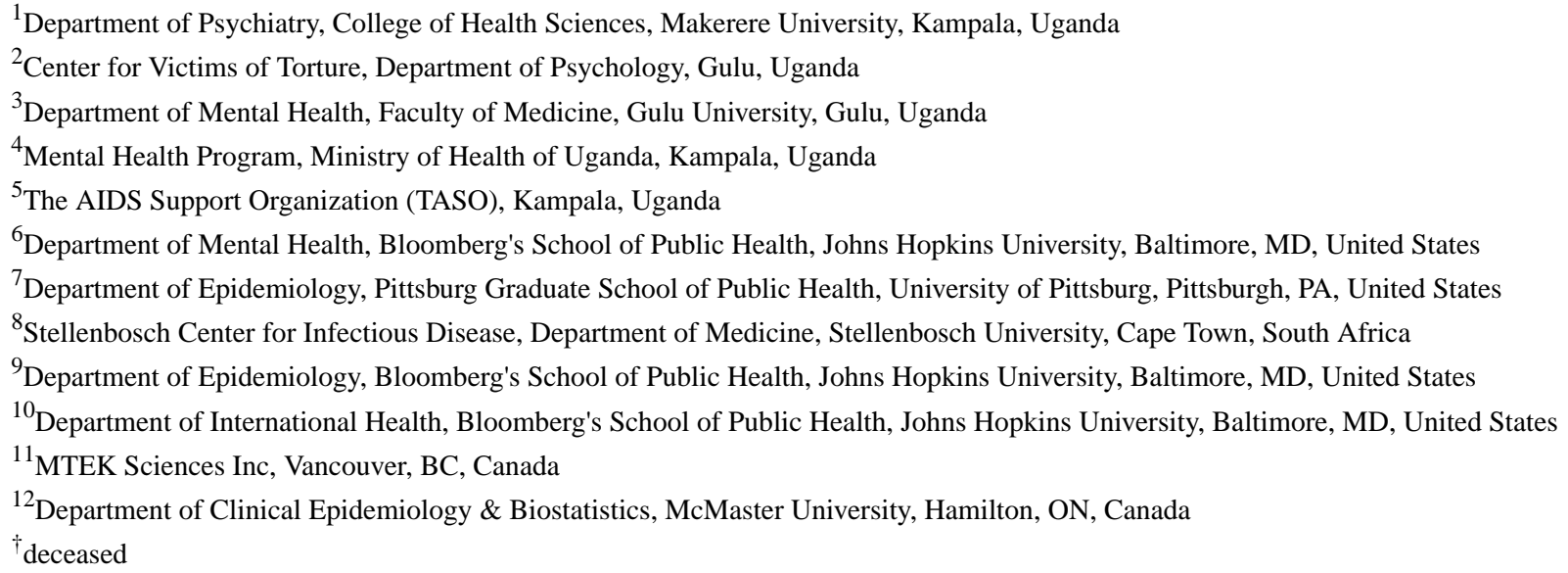

\section{Corresponding Author:}

Etheldreda Nakimuli-Mpungu, MMED(Psych), PhD

Department of Psychiatry

College of Health Sciences

Makerere University

Old Mulago Hospital Complex

Mulago Hill Road

Kampala, 256

Uganda

Phone: 256788994050

Email: ethelmpungu@yahoo.com

\section{Abstract}

Background: Psychosocial characteristics, including self-esteem, perceived social support, coping skills, stigma, discrimination, and poverty, are strongly correlated with depression symptoms. However, data on the extent of these correlations among persons living with HIV and the associations between psychosocial characteristics and HIV treatment outcomes are limited in sub-Saharan Africa.

Objective: This paper aims to describe the recruitment process and baseline characteristics associated with depression in a sample of HIV-positive people in a cluster randomized trial of group support psychotherapy (GSP) for depression delivered by trained lay health workers (LHWs).

Methods: Thirty eligible primary care health centers across three districts in Uganda were randomly allocated to have their LHWs trained to deliver GSP (intervention arm) or group HIV education and treatment as usual (control arm) to persons living with HIV comorbid with depression. Baseline demographic, socioeconomic, and psychosocial characteristics were collected via interviewer-administered questionnaires. Among eligible participants, differences between those enrolled versus those who refused 
enrollment were assessed using chi square for categorical variables and t tests for continuous variables. Spearman rank order correlation analyses were conducted to determine associations between baseline depression symptoms and adherence to antiretroviral therapy (ART), viral load suppression, and other psychosocial variables.

Results: The study screened 1473 people and 1140 were found to be eligible and enrolled over 14 weeks. Participants recruited comprised $95 \%$ of the target sample size of 1200. The sample's mean age was 38.5 (SD 10.9) years and both genders were well represented (males: $46.32 \%, 528 / 1140)$. Most participants met the diagnostic criteria for major depressive disorder (96.92\%, 1105/1140), had significant posttraumatic stress symptoms $(72.46 \%, 826 / 1140)$, reported moderate suicide risk $(52.54 \%, 599 / 1140)$, had primary or no formal education $(86.22 \%, 983 / 1140)$, and reported no income-generating activity $(72.63 \%, 828 / 1140)$ and no food insecurity $(81.67 \%, 931 / 1140)$. Among eligible participants, 48 of $1140(4.21 \%)$ refused to participate in the interventions; these participants were more likely to be males $\left(\chi_{1}^{2}=4.0, P=.045\right)$ and have significantly lower depression symptoms scores $\left(\mathrm{t}_{2}=2.36, P=.01\right)$ than those who participated in the interventions. There was a significant positive correlation between viral load and number of traumatic experiences $(\rho=.12, P=.05)$. Adherence to ART was positively correlated with perceived social support $(\rho=.15, P<.001)$, but negatively correlated with depression symptoms $(\rho=-.11, P=.05)$ and stigma $(\rho=-.14, P<.001)$.

Conclusions: Men and women with HIV and depression experience multiple social and economic vulnerabilities and disadvantages. Culturally tailored psychological interventions aimed at these individuals should address these socioeconomic disadvantages in addition to addressing their mental health care needs.

Trial Registration: Pan African Clinical Trials Registry PACTR201608001738234; https://pactr.samrc.ac.za/TrialDisplay.aspx?TrialID=1738 (Archived by WebCite at http://www.webcitation.org/74NtMphom)

(JMIR Res Protoc 2019;8(1):e11560) doi: $10.2196 / 11560$

\section{KEYWORDS}

cluster randomized trial; group support psychotherapy; lay health workers; depression; recruitment; psychosocial stressors; persons living with HIV/AIDS; Uganda

\section{Introduction}

Individuals with major depression account for a substantial proportion of antiretroviral therapy (ART) users attending HIV treatment centers in sub-Saharan Africa. Yet they hardly receive any mental health services [1,2]. Several studies in HIV-positive populations both in developed and developing countries have shown that psychosocial stressors, such as a lack of social support and poor coping skills [3,4], low self-esteem [5], lack of financial resources [6], and internalized stigma and discrimination $[7,8]$ are associated with depression. Furthermore, several studies conducted in HIV-positive populations have shown that alcohol use problems and posttraumatic stress are frequent and often complicate depression $[9,10]$. However, data on the extent of these correlations among persons living with HIV in sub-Saharan Africa are limited.

Past research studies in developed countries have shown that depression and related psychosocial stressors influence progression of HIV disease [11]. For example, there is some evidence that persons living with HIV (PLWH) who report experiencing stigma and discrimination have worse health outcomes [12]. Past research has also shown that lack of social support and poor coping skills [13], poor financial resources [14], and food insecurity [15] among ART users have been associated with poor HIV treatment outcomes. However, most past research on these associations come from high-income countries and from studies with small sample sizes. The correlations between psychosocial characteristics and HIV treatment outcomes in other parts of the world, and especially in sub-Saharan Africa where HIV is highly prevalent, are unknown.
Further, although studies of psychological interventions with depressed PLWH in high-income countries have endeavored to document related psychosocial stressors or HIV treatment outcomes [16], those conducted in low- and middle-income countries have rarely done so [17]. As a result, there is little information on the psychosocial stressors associated with HIV treatment from low- and middle-income countries. This makes it difficult to understand and appreciate the social context of PLWH in these settings. Past research from the United States has highlighted the role of various environmental stressors related to poverty, persistent residential mobility, racial discrimination, and inadequate access to resources on HIV care and outcomes. These findings indicate the importance of attending to social context in addition to clinical factors in planning interventions for PLWH [18].

To attend to the contextual realities of PLWH in sub-Saharan Africa, we developed group support psychotherapy (GSP) - a culturally sensitive cognitive behavioral-based intervention that treats depression by enhancing emotional and social support, positive coping, and livelihood skills [19]. The Social, Emotional, and Economic empowerment through Knowledge of GSP (SEEK-GSP) trial follows a series of pilot studies $[20,21]$ that demonstrated the effectiveness of GSP in treating mild to moderate depression. This trial will provide robust evidence for the change processes and outcomes we observed in these pilot studies.

The PLWH participating in the SEEK-GSP trial were recruited from a postconflict region where there is a heavy burden of depression, posttraumatic stress symptoms, and psychosocial stressors [22]. This sample provides an opportunity to understand the processes and challenges in recruiting this highly vulnerable population, who are rarely recruited into clinical 
trials. The purpose of this paper is to summarize the recruitment procedures and baseline results of this trial, and explore associations among depression symptoms, related psychosocial stressors, adherence to ART, and viral suppression.

\section{Methods}

\section{Overview of Study Design and Interventions}

A detailed description of the study protocol is published elsewhere [23] and is registered in the Pan African Clinical Trials Registry (PACTR201608001738234). Briefly, this is a pragmatic two-arm cluster randomized trial evaluating the effectiveness GSP delivered by trained lay health workers (LHWs) to PLWH presenting with mild to moderate depression in primary care. The study involves 30 primary health centers in three districts in northern Uganda that were randomly assigned (with a 1:1 ratio) to have their LHWs trained in the delivery of GSP (intervention) or group HIV education (control condition) to PLWH with mild to moderate depression. The PLWH treated by the trained LHWs were evaluated at baseline, at the end of intervention, and at intervals of 6 months thereafter for 2 years.

The development of the GSP and group HIV education interventions has been described in detail in previous publications [19,21]. A detailed description of the content of both interventions has also been previously published [24]. The study was submitted to and approved by the Makerere University College of Health Sciences Research Ethics Committee, The AIDS Support Organization Research Ethics Committee, and the Uganda National Council of Science and Technology. All study participants were required to provide written informed consent. Light refreshments were served during all group sessions in both arms, and each participant and group facilitator received a financial incentive amounting to 8000UGX (US \$2.16) and 80,000UGX (US \$21.62), respectively, at the end of treatment to defray transportation costs. Figure 1 summarizes the trial profile.

\section{Training of Health Workers}

\section{Group Support Psychotherapy Training}

Over a 4-month period (January to April 2016), Makerere University, in collaboration with the Ministry of Health, designed a GSP training program that consisted of both formal and informal training. This training was delivered using a training-of-trainers model in May and August 2016. Mental health specialists trained primary health center workers who, in turn, trained the LHWs. Formal training consisted of eight training modules delivered in a 5-day training workshop that employed active learning techniques including role plays, brainstorming sessions, and small group discussions. In brief, the first three modules included an overview of the training program, introduction to the GSP model, and an introduction to depression and HIV/AIDS were delivered on the first day. On the second and third days, modules on basic counseling skills and effective coping strategies were delivered, respectively. On the fourth day, participants received training in basic livelihood skills (enterprise selection, basic financial skills, and resource mobilization) required to overcome poverty. The last day of training focused on self-care strategies, posttraining assessments, and training workshop evaluation. Informal training consisted of conducting supervised pilot GSP sessions. Newly trained health workers were supervised by a pool of previously trained health workers who participated in the pilot randomized controlled trial [21]. The competencies targeted by the training have been published elsewhere [24]. Multimedia Appendix 1 shows the health worker supervision checklist used by supervisors.

\section{Group HIV Education Training}

In May 2016, Makerere University, in collaboration with The AIDS Support Organization, designed a group HIV education training program that consisted of both formal and informal training. Between May and August 2016, the training-of-trainers model was used to deliver the training, whereby The AIDS Support Organization HIV care providers trained primary health center workers who in turn trained the LHWs. Formal training consisted of five training modules delivered in a lecture format in a 2-day training workshop. In brief, on the first day, three modules including an overview of the training program, introduction to depression and HIV/AIDS, HIV progression, and transmission were delivered. On the second day, modules on mother-to-child transmission and basic facts on ART were delivered. Informal training consisted of conducting supervised pilot group HIV education sessions.

After both trainings, the trained LHWs initiated health education talks on depression in villages where they work and also among PLWH returning for medication refill. The PLWH who identified they had depression symptoms were invited for further evaluation. Those who met diagnostic criteria for mild to moderate depression were invited to attend group sessions of either GSP or group HIV education.

\section{Study Screening and Recruitment}

We used study teams that reflected the ethnicity of the target community at each of the participating primary health centers. The study teams worked with the trained LHWs, who are the first level of health care delivery in the country, to spread information about the study by word of mouth in villages within the study region. The LHWs are members of the village health team [25]. They know individuals in the community who are receiving HIV care and could approach them directly with information about the study.

The study team conducted presentations in the community to explain study purpose and procedures to facilitate community understanding of the trial activities. At each participating primary health center, trained LHWs gave health talks on depression to clients in the waiting area. Those who had experienced symptoms of depression described in the health talk were invited for further evaluations using the Luo version of the 20-item Self-Reporting Questionnaire (SRQ-20) and the Mini International Neuropsychiatric Interview (MINI) depression module [26]. 
Figure 1. Recruitment process. GHE: group HIV education; GSP: group support psychotherapy.

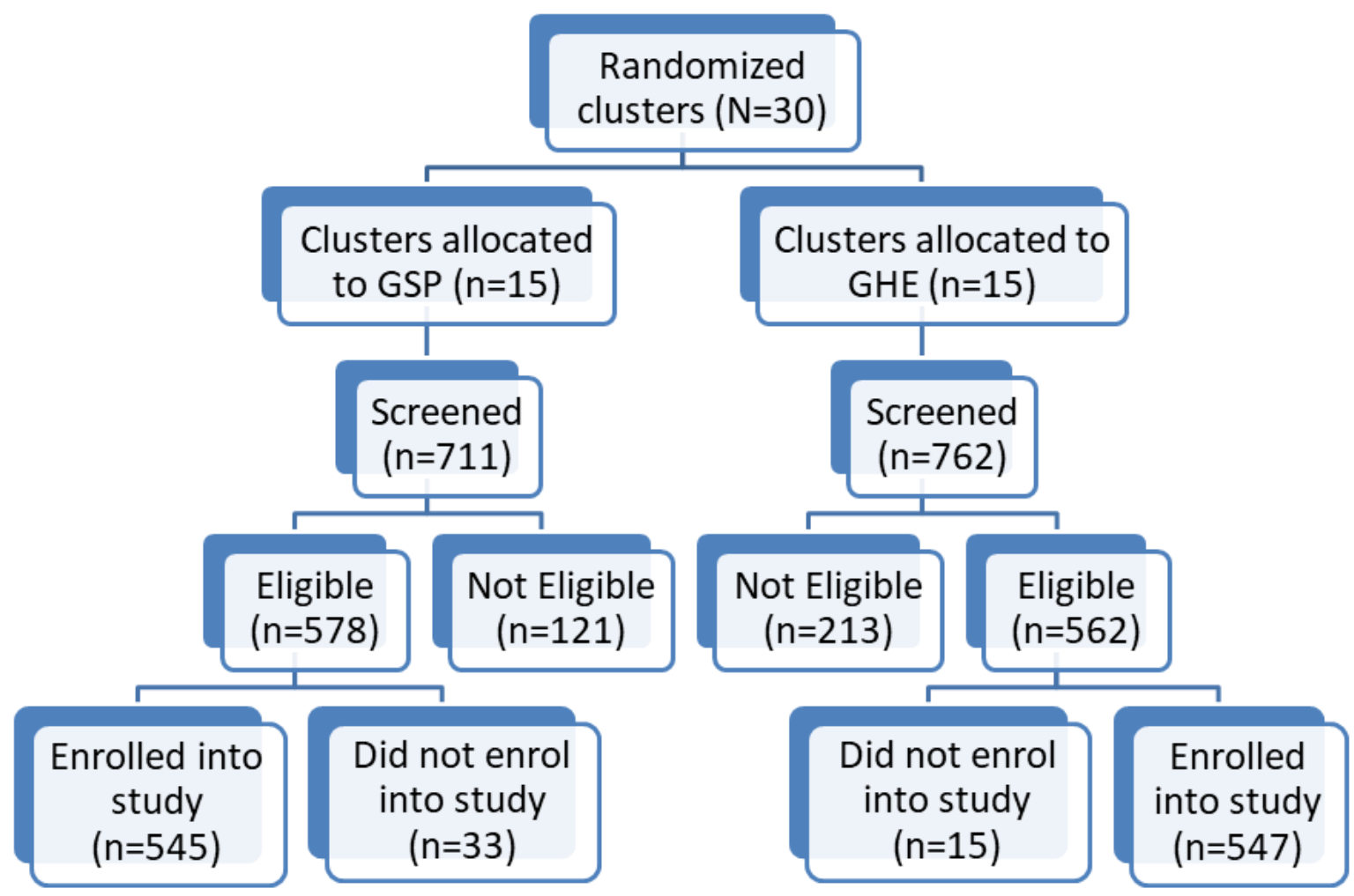

This procedure was repeated until a total of 40 PLWH meeting the MINI criteria of major depression were obtained from each primary health center. Research assistants approached each eligible client and explained study procedures, determined that other eligibility criteria were met and then obtained informed consent. To be recruited in the study, participants had to be HIV positive, aged 19 years or older, meet MINI criteria for major depressive disorder, antidepressant naïve, using ART, and residing in the villages where the trained LHWs lived. Individuals at high suicide risk [27], with a severe medical condition such as pneumonia or active tuberculosis, those with psychotic symptoms, or hearing or visual impairment were excluded from the study. Recruited participants from the same village were assigned to a trained LHW residing in or near their village to receive the intervention they had been trained to deliver (ie, either GSP or group HIV education).

\section{Study Measures}

A structured questionnaire administered in the local language was used to collect data on a number of baseline variables in one-on-one, face-to-face interviews.

\section{Baseline Sociodemographic Variables}

Sociodemographic variables were assessed using a demographic questionnaire that asked about descriptive information including age, gender, number of children, education, and relationship and employment status. Employment status was categorized into "unemployed," "employed," and "peasant farmer." Relationship status was categorized into "never married," "married/living with a partner," "divorced/ separated," or "widowed." Education status was categorized into "primary/no formal education" and "secondary and above."

\section{Baseline Psychiatric and Psychosocial Variables}

\section{Major Depressive Disorder}

Major depressive disorder was diagnosed with the MINI depression module. The MINI is a diagnostic structured interview that was developed for the Diagnostic and Statistical Manual of Mental Disorders (4th Edition) of psychiatric disorders [26]. The psychometric properties of the MINI have not been described in Uganda; however, its depression diagnostic section has been translated and locally adapted in Luganda and previously used in this setting [28]. The depression diagnostic section consists of two screening questions, seven additional questions related to depression symptoms, and one question related to functional impairment. The two screening questions ask about the presence of depressed mood and loss of interest in daily activities over a period of 4 weeks in the recent past. If either one or both questions were positively endorsed by a study participant, the clinician asked additional questions to explore current (ie, 4 weeks before the interview) major depressive disorder. A diagnosis of current major depressive disorder was made if a study participant positively endorsed five or more questions related to depression symptoms 
and the one question related to functional impairment over a 4-week period.

\section{Depression Symptoms}

Depression symptoms were assessed using the SRQ-20 [29]. Cross-cultural adaptation and validation of the SRQ-20 in PLWH in southern Uganda showed that an optimum cut-off point of six or higher had a sensitivity of $84 \%$ and a specificity of $93 \%$ for current depression [30]. In this study sample, SRQ scores were modeled as a continuous variable with a Cronbach alpha reliability coefficient of .77 .

\section{Functioning Level}

We assessed functioning levels using a five-item locally developed function assessment method [24]. Items were derived from qualitative interviews with individuals and their caregivers who were attending psychotrauma centers in Kitgum and Gulu [31].

In this population, the measure attained a Cronbach alpha of .86. The scale consisted of five categories of tasks including household (eg, washing clothes, sweeping the yard), work in the field (eg, digging, grazing animals), social interactions (eg, attending social events), and job-related or school-related tasks (eg, participating in income-generating activities, attending school or skills-training courses) and tasks related to personal hygiene (eg, bathing). Study participants were asked to indicate their ability to do a given task on a three-point scale where 0 referred to those who responded "no, I am not able," 1 to "yes, but not like before," and 2 to "yes, I am able to."

\section{Disability Days}

We assessed disability days by asking a single question "How many working days have you lost due to depression-related symptoms in the previous 30 days?" Disability days reported were modeled as a continuous variable.

\section{Posttraumatic Stress Symptoms}

Posttraumatic stress symptoms were assessed using the locally adapted Harvard Trauma Questionnaire. It has been successfully translated into several languages, with acceptable measures of reliability and validity [32]. In this study population, the measure attained a Cronbach alpha reliability coefficient of .93 .

\section{Traumatic Experiences}

War-related traumatic experiences were assessed using a locally developed 16-item trauma event checklist. Participants were asked whether they had experienced a given traumatic event or not. The trauma event checklist included items such as "Has the patient been forced to torture others?" "Has the patient witnessed torture/killing of another person?" "Has the patient been forced to kill?" A variable indicating the number of traumatic experiences by an individual was created and modeled as a continuous variable.

\section{Perceived Social Support:}

Perceived social support was assessed with the 12-item multidimensional social support scale [33]. The scale has been validated in Uganda and its three-subscale structure (family, friends, and significant other) was confirmed [34]. The Cronbach alpha for this sample was .96. Responses were based on a seven-point Likert scale with higher scores indicating greater support from friends, family, and significant others. We obtained total scores from the scale and modeled the scores as a continuous variable.

\section{Self-Esteem}

Self-esteem was measured using the 10-item Rosenberg Self-Esteem Scale, which provides assessment of one's general feelings about oneself [35]. Responses were based on a four-point scale. This scale has been used in HIV-positive women in South Africa [36]. The scores range from 10 to 40 with higher scores indicating higher self-esteem. We obtained total scores from the scale and modeled the scores as a continuous variable. In this study sample, the measure attained a Cronbach alpha of .93 .

\section{Alcohol Use}

We assessed alcohol use with the Alcohol Use Disorders Identification Test (AUDIT) [37]. This 10-item scale has been validated in PLWH populations in sub-Saharan Africa [10]. Each of the 10 questions is rated on a four-point scale. The total score ranges from 0 to 40 . A total of eight or higher is recommended as an indicator of hazardous drinking behavior and a score of 20 or higher is indicative of alcohol dependence. We report this variable both as categorical using the cut-off point of eight or higher and continuous using total AUDIT scores. In this study population, the measure attained a Cronbach alpha of .95 .

\section{Coping Skills}

We used the modified coping inventory to assess a broad range of both positive and negative coping responses which establish how the study participants responded when they were confronted with difficult or stressful events in their lives [38]. Each coping strategy is assessed by a set of two questions. Responses were based on a four-point scale. For each coping strategy, the scores range from two to eight, with higher scores indicating frequent use of the coping strategy. Each coping strategy was modeled as a continuous variable.

\section{Stigma and Discrimination}

To measure internalized stigma, we used the brief AIDS-related stigma scale [39]. Responses were based on a four-point Likert scale. The scores ranged from 8 to 32 with high scores indicating higher levels of internalized stigma.

To measure discrimination (enacted stigma), we used a total of 13 items adapted from an HIV/AIDS indicator survey previously used by Nyblade and MacQuarrie [40] which described various forms of discriminatory events experienced by PLWH as a result of their HIV status. Both stigma and discrimination were modeled as continuous variables.

\section{Viral Load}

Once a year, HIV treatment centers routinely assess the viral load of clients. Measures of viral load were obtained from the medical charts of study participants. Although the name of the assay used to measure viral load in the laboratory was not recorded, all viral load measures were conducted by the same laboratory. If the record in the chart noted undetectable viral copies, that individual was assumed to have achieved viral 
suppression. If there was a record of detected viral copies in the chart, these were transcribed to the study questionnaire. Viral load was treated both as a continuous variable and as a categorical variable indicating suppression (coded 1) or nonsuppression of viral load (coded 0$)$.

\section{Adherence to Antiretroviral Therapy}

Adherence to ART was assessed by using the missed-dose method, which is simple to implement and straightforward. Participants were asked to report the number of missed doses within a specified time period. We asked a single question: "During the past week, on how many days have you missed taking all your medication doses?" Adherence was calculated as the percent of days in the week the person missed all medications. Adherence "scores" were treated both as a continuous variable in correlation analyses and also converted to a dichotomous variable (eg, adherent/nonadherent) to simplify their interpretation for the descriptive analyses. In previous studies, researchers have used either $80 \%$ or $90 \%$ or $100 \%$ as the cut-off point for adherence $[41,42]$. In this study, we used $100 \%$ as the cut-off point.

\section{Socioeconomic Status Index}

To evaluate the baseline socioeconomic status (SES) of study participants, we created an SES index using principal component analysis of the following variables: presence or absence of an income-generating activity, food security, savings, and household assets (land, animals, poultry, radio, television, mobile phone, bicycle, or motorcycle). The index was categorized into quintiles with the first quintile representing low SES, the second to fourth quintiles representing the medium SES, and the fifth quintile representing the high SES group.

\section{Statistical Analyses}

Statistical analyses were performed using STATA statistical software version 15. Descriptive statistics were used to describe the demographic, clinical, and psychosocial characteristics of the study population. Among eligible participants, differences between those enrolled versus those who refused enrollment were assessed using chi square tests for categorical variables and $t$ tests for continuous variables. Due to violations of normality, nonlinear relationships and the presence of ordinal variables, we opted to use the nonparametric Spearman rank order correlation ( $\rho$ coefficient) to examine associations between depression symptoms and other baseline variables. A Bonferroni adjustment was applied to calculated significance levels. Statistical significance was considered at two-tailed $P \leq .05$.

\section{Results}

\section{Screening and Recruitment}

The study recruitment period was from September to December 2016. After a series of health talks on depression in 30 participating primary health centers, a total of 1473 individuals expressed interest in being screened for depression. Of these, 1140 were eligible and enrolled in the study. On commencement of the interventions, $48(4.21 \%)$ did not attend any group session. Of these, 21 had failed to complete baseline assessments, while 27 had completed baseline assessments. Although these participants appeared to have withdrawn from the study after enrollment, they did not announce their exit. Therefore, we still consider them as part of the study. Figure 1 summarizes the recruitment process.

The study was able to recruit $95 \%$ the target sample size of 1200 described in the study protocol. The target of 40 participants in each health center was met by only 14 primary health centers. Only 23 participants were enrolled outside the target enrollment period. Multimedia Appendices 2 and 3 show the geographical distribution of the primary health centers and the actual enrollment versus target enrollment, respectively.

Other protocol deviations reported included the enrollment of 141 of $1140(12.37 \%)$ individuals who did not meet the MINI criteria for major depression. However, of those enrolled, 127 of $1140(11.14 \%)$ were judged to be clinically depressed by the health workers and had attained a score of more than six on the SRQ-20, which indicates a high probability of major depression [30]. In addition, 13 of $1140(1.14 \%)$ did not meet the criteria for depression and 22 of 1140 (2.02\%) did not have a record of their depression status. Individuals with high suicide risk were to be excluded from the study; however, for 32 of $1140(2.80 \%)$ individuals with high suicide risk, the health workers insisted that they be included in the study as the group sessions were the only interventions accessible at that time and it would be unethical if they did not receive any form of intervention for their depression. Multimedia Appendix 4 illustrates details of the protocol deviations.

\section{Baseline Characteristics of Study Participants}

The sample consisted of slightly more women (612/1140, $53.68 \%)$ than men $(528 / 1140,46.32 \%)$. The age of participants ranged from 19 to 80 years, with a mean age of 38.5 (SD 10.9) years. The majority were peasant farmers $(622 / 1140,54.56 \%)$, with primary level education or less $(983 / 1140,86.22 \%)$, without an income-generating activity (828/1140, 72.63\%), and without food security $(931 / 1140,81.67 \%)$. Most participants met criteria for major depression $(1105 / 1140,96.92 \%)$ at baseline, as described previously, and reported moderate suicide risk (599/1140, 52.54\%). Participants' function scores ranged from 0 to 10 , with a mean function score of 4.98 (SD 2.91). In all, $72.46 \%$ of study participants $(826 / 1140)$ met the criteria for probable posttraumatic stress disorder, and $27.46 \%$ (313/1140) met the criteria for hazardous alcohol consumption. Tables 1 and 2 provide detailed descriptions of participant baseline sociodemographic and psychosocial characteristics, respectively.

Participants who did not attend any group sessions were significantly more likely to be male than females $\left(\chi_{1}^{2}=4.0\right.$, $P=.045)$ and on average had more depression symptoms $\left(t_{2}=2.36, P=.01\right)$ than participants who attended group sessions. Table 3 provides detailed comparisons of study participants who attended versus those who did not attend any group sessions. 
Table 1. Baseline sociodemographic characteristics of the study participants $(\mathrm{N}=1140)$.

\begin{tabular}{|c|c|}
\hline Variable & Participants \\
\hline \multicolumn{2}{|l|}{ Age (years) } \\
\hline Mean (SD) & $38.5(10.9)$ \\
\hline Range & $19-80$ \\
\hline \multicolumn{2}{|l|}{ Gender, $\mathbf{n}(\%)$} \\
\hline Female & $612(53.68)$ \\
\hline Male & $528(46.32)$ \\
\hline \multicolumn{2}{|l|}{ Educational background, n (\%) } \\
\hline Primary education or lower & $983(86.23)$ \\
\hline Secondary education or higher & $157(13.77)$ \\
\hline \multicolumn{2}{|l|}{ Employment status, n (\%) } \\
\hline Not employed & $405(35.53)$ \\
\hline Employed & $113(9.91)$ \\
\hline Peasant farmer & $622(54.56)$ \\
\hline \multicolumn{2}{|l|}{ Relationship status, n (\%) } \\
\hline Never married & $151(13.25)$ \\
\hline Married or living with partner & $816(71.58)$ \\
\hline Separated or divorced & $87(7.63)$ \\
\hline Widowed & $86(754)$ \\
\hline \multicolumn{2}{|c|}{ Has income-generating activity, $\mathrm{n}(\%)$} \\
\hline Yes & $312(22.37)$ \\
\hline No & $828(72.63)$ \\
\hline \multicolumn{2}{|l|}{ Has savings, $\mathrm{n}(\%)$} \\
\hline Yes & $302(26.49)$ \\
\hline No & $838(73.51)$ \\
\hline \multicolumn{2}{|c|}{ Has a leadership position in the community, n (\%) } \\
\hline Yes & $171(15.00)$ \\
\hline No & $648(85.00)$ \\
\hline \multicolumn{2}{|l|}{ Has food security, n (\%) } \\
\hline Yes & $209(18.33)$ \\
\hline No & $931(81.67)$ \\
\hline \multicolumn{2}{|l|}{ Number of children } \\
\hline Mean (SD) & $4.0(2.0)$ \\
\hline Range & $0-16$ \\
\hline \multicolumn{2}{|l|}{ Disability days in the past month } \\
\hline Mean (SD) & $8.5(9.2)$ \\
\hline Range & $0-30$ \\
\hline \multicolumn{2}{|l|}{ Baseline monthly income (UGX) } \\
\hline Mean (SD) & $7476(17,651)$ \\
\hline Range & $0-150,000$ \\
\hline \multicolumn{2}{|l|}{ Baseline savings(UGX) } \\
\hline Mean (SD) & $13,758(40,964)$ \\
\hline Range & $0-400,000$ \\
\hline
\end{tabular}




\begin{tabular}{ll}
\hline Variable & Participants \\
\hline Social economic status index & \\
Low (quintile 1) & $342(38.78)$ \\
Medium (quintiles 2-4) & $485(54.99)$ \\
High (quintile 5) & $55(6.24)$ \\
Missing & $258(22.63)$ \\
\hline
\end{tabular}

Table 2. Baseline psychosocial characteristics of the study participants $(\mathrm{N}=1140)$.

\begin{tabular}{|c|c|}
\hline Variable & Participants \\
\hline \multicolumn{2}{|l|}{ Major depression, n (\%) } \\
\hline Met MINI criteria & $978(85.78)$ \\
\hline Clinically depressed & $127(11.14)$ \\
\hline Did not meet any criteria & $13(1.14)$ \\
\hline Missing data & $22(1.93)$ \\
\hline \multicolumn{2}{|l|}{ Suicide risk, n (\%) } \\
\hline Low & $479(42.02)$ \\
\hline Moderate & $599(52.54)$ \\
\hline High & $32(2.80)$ \\
\hline Missing & $30(2.63)$ \\
\hline Depression score, mean (SD); range & $13.6(4) ; 0-20$ \\
\hline Posttraumatic stress score, mean (SD); range & $42.6(12.5) ; 16-64$ \\
\hline Function score, mean (SD); range & $5(2.9) ; 0-10$ \\
\hline Social support score, mean (SD); range & $44(20) ; 0-84$ \\
\hline Self-esteem score, mean (SD); range & $14(8) ; 0-32$ \\
\hline Internalized stigma score, mean (SD); range & $22(5) ; 8-32$ \\
\hline Alcohol Use(AUDIT) score, mean (SD); range & $6(9.0) ; 0-40$ \\
\hline \multicolumn{2}{|l|}{ Positive coping skills, mean (SD); range } \\
\hline Self-distraction & $3.7(2.0) ; 2-8$ \\
\hline Active coping & $4.2(2.0) ; 1-8$ \\
\hline Use of emotional support & $4(2) ; 2.0-8$ \\
\hline Use of venting & $3.9(2.0) ; 2-8$ \\
\hline Acceptance & $4.2(2.0) ; 1-8$ \\
\hline Use of positive reframing & $4(2.0) ; 1-8$ \\
\hline Use of religion & $4.7(2.0) ; 0-8$ \\
\hline \multicolumn{2}{|l|}{ Negative coping skills, mean (SD); range } \\
\hline Denial & $5(2.0) ; 0-8$ \\
\hline Self-blame & $2.8(1.2) ; 0-4$ \\
\hline Use of alcohol and substances & 4.55 (2.6); 0-8 \\
\hline Behavioral disengagement & $5.2(2.0) ; 0-8$ \\
\hline \multicolumn{2}{|l|}{ Enacted stigma (discrimination), mean (SD); range } \\
\hline Isolation & $2.8(3.0) ; 0-10$ \\
\hline Verbal abuse & $2.2(1.4) ; 0-4$ \\
\hline Loss of identity & $1.2(1.2) ; 0-4$ \\
\hline Unable to access community resources & $2.6(3.0) ; 0-10$ \\
\hline
\end{tabular}


Table 3. A comparison of eligible study participants who attended versus those who did not attend any group sessions ( $\mathrm{N}=1140)$.

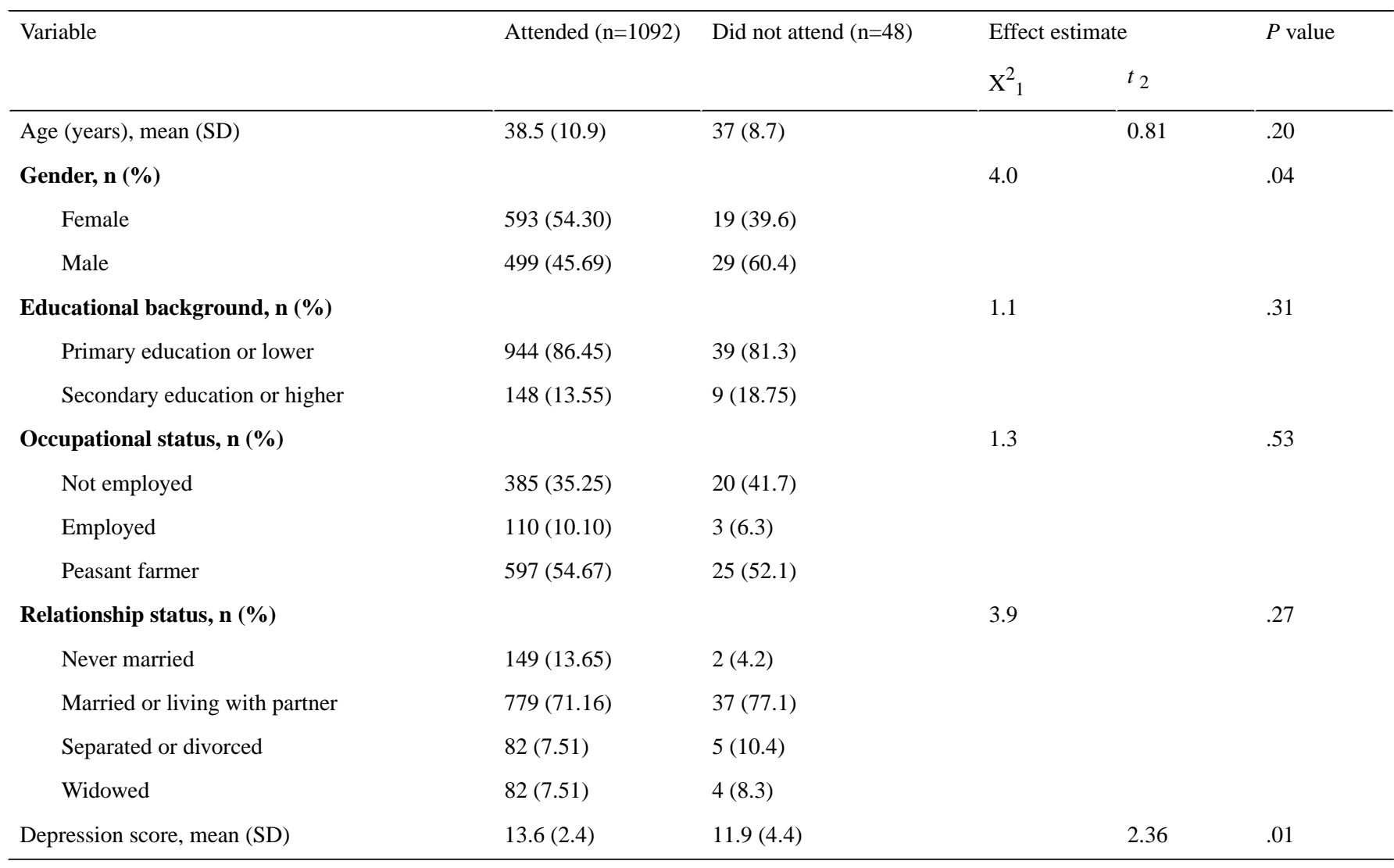

\section{Correlations Among Depression and Related Psychosocial Variables}

There were several significant associations found between depression symptoms and both clinical and psychosocial variables at baseline. Depression symptoms assessed by the MINI were positively correlated with posttraumatic stress symptoms $(\rho=.43, P<.001)$, suicide risk $(\rho=.32, P<.001)$, stigma $(\rho=.30, P<.001)$, number of traumatic experiences $(\rho=.25$, $P<.001$ ), and negatively correlated with perceived social support $(\rho=-.35, P<.001)$, functioning $(\rho=-.22, P<.001)$, self-esteem $(\rho=-.39, P<.001)$, and adherence to $\operatorname{ART}(\rho=-.12, P=.05)$. Suicide risk was positively correlated with posttraumatic stress symptoms $(\rho=.28, P<.001)$, number of traumatic experiences $(\rho=.21, P<.001)$, stigma $(\rho=.2, P<.001)$, and alcohol use $(\rho=.21$, $P<.001)$.

Adherence to ART was positively correlated with social support $(\rho=.15, P<.001)$ and negatively correlated with stigma $(\rho=-.14$, $P<.001)$. The number of traumatic experiences was positively correlated with viral load $(\rho=.12, P=.05)$. Correlations between viral load and depression symptoms were positive but weak and nonsignificant. See Table 4 for the correlation matrix. 
Table 4. Baseline correlations among depression symptoms and related psychosocial variables $(\mathrm{N}=1140)$. $* P<.001 ; * * P<.05$.

\begin{tabular}{|c|c|c|c|c|c|c|c|c|c|c|c|c|}
\hline $\begin{array}{l}\text { Symptoms and } \\
\text { variables }\end{array}$ & Depression & $\begin{array}{l}\text { Suicide } \\
\text { risk }\end{array}$ & Function & PTSD $^{\mathrm{a}}$ & $\begin{array}{l}\text { Social } \\
\text { support }\end{array}$ & $\begin{array}{l}\text { Self-es- } \\
\text { teem }\end{array}$ & Stigma & $\begin{array}{l}\text { Viral } \\
\text { load }\end{array}$ & $\begin{array}{l}\text { Adher- } \\
\text { ence }\end{array}$ & Trauma & $\begin{array}{l}\text { Alcohol } \\
\text { Use }\end{array}$ & $\begin{array}{l}\text { SES } \\
\text { Index }\end{array}$ \\
\hline \multicolumn{13}{|l|}{ Depression } \\
\hline Suicide risk & $.32 *$ & & & & & & & & & & & \\
\hline Function & $-.22 *$ & $-.17 *$ & & & & & & & & & & \\
\hline Social support & $-.35^{*}$ & $-.22 *$ & $.28 *$ & $-.33^{*}$ & & & & & & & & \\
\hline Self-esteem & $-.40 *$ & $-.21 *$ & $.51 *$ & $-.48^{*}$ & $.46^{*}$ & & & & & & & \\
\hline Stigma & $.30 *$ & $.20^{*}$ & $-.26^{*}$ & $.28 *$ & $-.33^{*}$ & $-.42 *$ & & & & & & \\
\hline Viral load & .02 & .05 & .07 & -.02 & .04 & .08 & -.06 & & & & & \\
\hline Trauma & $.24 *$ & $.21 *$ & $-.11 * *$ & $.13^{*}$ & -.06 & -.08 & .05 & $.12 * *$ & .05 & & & \\
\hline Alcohol use & -.08 & $.22 *$ & .04 & -.06 & -.01 & .09 & .06 & -.05 & .01 & $.13 *$ & 1.00 & \\
\hline SES Index & -.04 & $.15^{*}$ & .02 & -.03 & .09 & .07 & -.02 & .03 & -.01 & .02 & 0.02 & 1.00 \\
\hline
\end{tabular}

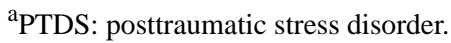

${ }^{\mathrm{a}} \mathrm{SES}$ : socioeconomic status.

\section{Discussion}

The SEEK-GSP study tests GSP delivered by trained LHW for treatment of depression in rural areas in postconflict northern Uganda. The recruitment goal for the study was largely achieved, with $95 \%$ of the targeted sample size enrolled in the trial in a 14-week period. This finding suggests that participants were easy to recruit for the study and were willing to participate in either study arm. In contrast to previous trials of psychological interventions for depression in sub-Saharan Africa [43-45], 80\% of those recruited in the study attended all group sessions. This high attendance, which was also observed in our previous pilot trial [24], indicates keen interest and confirms the acceptability of group interventions in the target population.

Among trials of psychological interventions to treat depression in PLWH in sub-Saharan Africa, this study is the first to enroll a large sample of males. The majority of previous trials of psychological interventions for depression have largely focused on women, including studies by Kaaya and colleagues from Tanzania [44], Chibanda and colleagues from Zimbabwe [45], and Bolton and colleagues from southern Uganda [46]. These studies are important given the dearth of prior studies focused on psychological treatments for depression in sub-Saharan Africa. However, interventions that attract men may be particularly relevant to African communities and may be a promising avenue for engaging them in research and, if e cacious, improving the health of the entire community.

The baseline data from this study indicate that PLWH with depression are vulnerable on multiple levels and disadvantaged across many social and economic determinants of health. The majority have low education, lack an income-generating activity and food security, and on average were unable to work for 10 days in the month prior to enrollment. These findings are not surprising. Such socioeconomic disadvantage has been documented among HIV-positive populations across the African continent $[47,48]$ and is often associated with depression $[49,50]$.

Correlation analyses indicate that there are significant positive and negative correlations between depression symptoms and other baseline variables. The positive correlations between depression and posttraumatic symptoms, internalizing stigma and number of traumatic experiences, are not surprising. Several studies have demonstrated the comorbidity of stigma, depression, and posttraumatic stress symptoms in primary care settings [51-53].

Among the negative correlations, a larger number of depression symptoms were associated with lower levels of functioning, perceived social support, and self-esteem. Previous studies have confirmed that depression impairs functioning [54,55], while social support is the most potent buffer against depression [56-58]. Further, a meta-analysis of 77 longitudinal studies provides consistent support for the fact that low self-esteem contributes to depression [5].

Our study findings further indicate that with a larger number of depression symptoms, there is a lesser degree of adherence to ART, confirming what a myriad of previous studies have shown worldwide [59]. We also found a significant positive correlation between the number of traumatic experiences and viral load. Prior longitudinal studies in high-income countries have found a similar association [60,61]. However, such an association has not been documented among PLWH in sub-Saharan Africa. Overall, our study findings justify the active ingredients of our experimental intervention-GSP which places emphasis on enhancing emotional and social support, coping skills to combat stigma and discrimination, and support economic empowerment.

This study has a number of limitations. Although our data are drawn from multiple HIV clinics across three districts in northern Uganda, the study participants share the same ethnicity. 
Given that Uganda is a multiethnic country, our results may not be applicable to other ethnic populations. The study needs to be replicated in other regions of the country. Self-report is not the most reliable measure of ART adherence; therefore, our adherence estimates may represent an overestimate. However, a gold standard for adherence assessment does not exist and different assessment methods have been used in different studies [62].

Despite these limitations, the SEEK-GSP study provides a rich dataset with follow-up of the high number of persons with major depressive disorder and HIV disease in sub-Saharan Africa. The large sample size will allow us to conduct subgroup analyses to assess how some variables, such as gender and psychiatric comorbidities (hazardous alcohol consumption and posttraumatic stress), can modify the effects of GSP on depression. Identifying groups of individuals for whom GSP works best will assist future work toward developing selection criteria to guide referral of patients for GSP. Additionally, variables that mediate the effects of GSP on depression, and subsequently other study outcomes, can thus be identified.

\section{Acknowledgments}

The SEEK-GSP study is funded by Grand Challenges Canada (Grant \#0770-05) and the MQ Mental Health Fellowship Award (Grant \#MQ15FIP100024). The funders of the study had no role in study design, data collection, data analysis, data interpretation, or writing of the report.

\section{Authors' Contributions}

EN-M, KW, JO, SM, RM, JB, EM, and JN conceptualized the study and EN-M sought and obtained funding. EM and OH conducted statistical analyses. EN-M and JO managed the literature searches. EN-M, RM, EM, and JN wrote the initial manuscript. SM, RM, HM, ME, EM, and JN revised the manuscript critically for important intellectual content. All authors contributed to the final manuscript.

\section{Conflicts of Interest}

None declared.

\section{Multimedia Appendix 1}

Health Worker Supervision Checklist.

[PDF File (Adobe PDF File), 275KB-Multimedia Appendix 1]

\section{Multimedia Appendix 2}

Geographical distribution of primary health care centers in the study.

[PNG File, 601KB-Multimedia Appendix 2]

\section{Multimedia Appendix 3}

Actual versus expected enrolment of study participants.

[PNG File, 115KB-Multimedia Appendix 3]

\section{Multimedia Appendix 4}

Study protocol deviations.

[PDF File (Adobe PDF File), 16KB-Multimedia Appendix 4]

\section{References}

1. Nakimuli-Mpungu E, Bass JK, Alexandre P, Mills EJ, Musisi S, Ram M, et al. Depression, alcohol use and adherence to antiretroviral therapy in sub-Saharan Africa: a systematic review. AIDS Behav 2012 Nov;16(8):2101-2118. [doi: 10.1007/s10461-011-0087-8] [Medline: 22116638]

2. Bernard C, Dabis F, de Rekeneire N. Prevalence and factors associated with depression in people living with HIV in sub-Saharan Africa: A systematic review and meta-analysis. PLoS One 2017;12(8):e0181960 [FREE Full text] [doi: 10.1371/journal.pone.0181960] [Medline: 28783739]

3. Li L, Lin C, Liang L, Ji G. Exploring coping and social support with gender and education among people living with HIV in China. AIDS Behav 2016 Feb;20(2):317-324 [FREE Full text] [doi: 10.1007/s10461-015-1232-6] [Medline: 26494110]

4. Yeji F, Klipstein-Grobusch K, Newell M, Hirschhorn LR, Hosegood V, Bärnighausen T. Are social support and HIV coping strategies associated with lower depression in adults on antiretroviral treatment? Evidence from rural KwaZulu-Natal, South Africa. AIDS Care 2014;26(12):1482-1489. [doi: 10.1080/09540121.2014.931561] [Medline: 24991994] 
5. Sowislo JF, Orth U. Does low self-esteem predict depression and anxiety? A meta-analysis of longitudinal studies. Psychol Bull 2013 Jan;139(1):213-240. [doi: 10.1037/a0028931] [Medline: 22730921]

6. Familiar I, Murray S, Ruisenor-Escudero H, Sikorskii A, Nakasujja N, Boivin MJ, et al. Socio-demographic correlates of depression and anxiety among female caregivers living with HIV in rural Uganda. AIDS Care 2016 Dec;28(12):1541-1545 [FREE Full text] [doi: 10.1080/09540121.2016.1191609] [Medline: 27240825]

7. Mahajan AP, Sayles JN, Patel VA, Remien RH, Sawires SR, Ortiz DJ, et al. Stigma in the HIV/AIDS epidemic: a review of the literature and recommendations for the way forward. AIDS 2008 Aug;22 Suppl 2:S67-S79 [FREE Full text] [doi: 10.1097/01.aids.0000327438.13291.62] [Medline: 18641472 ]

8. Lowther K, Selman L, Harding R, Higginson IJ. Experience of persistent psychological symptoms and perceived stigma among people with HIV on antiretroviral therapy (ART): a systematic review. Int J Nurs Stud 2014 Aug;51(8):1171-1189. [doi: 10.1016/j.ijnurstu.2014.01.015] [Medline: 24602830]

9. Olley BO, Zeier MD, Seedat S, Stein DJ. Post-traumatic stress disorder among recently diagnosed patients with HIV/AIDS in South Africa. AIDS Care 2005 Jul;17(5):550-557. [doi: 10.1080/09540120412331319741] [Medline: 16036241]

10. Myer L, Smit J, Roux LL, Parker S, Stein DJ, Seedat S. Common mental disorders among HIV-infected individuals in South Africa: prevalence, predictors, and validation of brief psychiatric rating scales. AIDS Patient Care STDS 2008 Feb;22(2):147-158. [doi: 10.1089/apc.2007.0102] [Medline: 18260806]

11. Boarts JM, Sledjeski EM, Bogart LM, Delahanty DL. The differential impact of PTSD and depression on HIV disease markers and adherence to HAART in people living with HIV. AIDS Behav 2006 May;10(3):253-261. [doi: 10.1007/s10461-006-9069-7] [Medline: 16482405]

12. Katz IT, Ryu AE, Onuegbu AG, Psaros C, Weiser SD, Bangsberg DR, et al. Impact of HIV-related stigma on treatment adherence: systematic review and meta-synthesis. J Int AIDS Soc 2013 Nov 13;16(3 Suppl 2):18640 [FREE Full text] [Medline: 24242258]

13. Ironson G, O'Cleirigh C, Kumar M, Kaplan L, Balbin E, Kelsch CB, et al. Psychosocial and neurohormonal predictors of HIV disease progression (CD4 cells and viral load): a 4 year prospective study. AIDS Behav 2015 Aug;19(8):1388-1397 [FREE Full text] [doi: 10.1007/s10461-014-0877-x] [Medline: 25234251]

14. Delpierre C, Cuzin L, Lauwers-Cances V, Datta GD, Berkman L, Lang T. Unemployment as a risk factor for AIDS and death for HIV-infected patients in the era of highly active antiretroviral therapy. Sex Transm Infect 2008 Jun;84(3):183-186. [doi: 10.1136/sti.2007.027961] [Medline: 18192292]

15. Aibibula W, Cox J, Hamelin A, McLinden T, Klein MB, Brassard P. Association between food insecurity and HIV viral suppression: a systematic review and meta-analysis. AIDS Behav 2017 Mar;21(3):754-765. [doi: 10.1007/s10461-016-1605-5] [Medline: 27837425]

16. van der Heijden I, Abrahams N, Sinclair D. Psychosocial group interventions to improve psychological well-being in adults living with HIV. Cochrane Database Syst Rev 2017 Mar 14;3:CD010806 [FREE Full text] [doi:

10.1002/14651858.CD010806.pub2] [Medline: 28291302]

17. Chibanda D, Cowan FM, Healy JL, Abas M, Lund C. Psychological interventions for common mental disorders for people living with HIV in low- and middle-income countries: systematic review. Trop Med Int Health 2015 Jul;20(7):830-839 [FREE Full text] [doi: 10.1111/tmi.12500] [Medline: 25753741]

18. Murry VM, Brown PA, Brody GH, Cutrona CE, Simons RL. Racial discrimination as a moderator of the links among stress, maternal psychological functioning, and family relationships. J Marriage and Family 2001 Nov;63(4):915-926. [doi: 10.1111/j.1741-3737.2001.00915.x]

19. Nakimuli-Mpungu E, Wamala K, Okello J, Alderman S, Odokonyero R, Musisi S, et al. Developing a culturally sensitive group support intervention for depression among HIV infected and non-infected Ugandan adults: a qualitative study. J Affect Disord 2014 Jul;163:10-17. [doi: 10.1016/j.jad.2014.03.042] [Medline: 24836082]

20. Nakimuli-Mpungu E, Wamala K, Okello J, Alderman S, Odokonyero R, Musisi S, et al. Outcomes, feasibility and acceptability of a group support psychotherapeutic intervention for depressed HIV-affected Ugandan adults: a pilot study. J Affect Disord 2014 Sep;166:144-150. [doi: 10.1016/j.jad.2014.05.005] [Medline: 25012423]

21. Nakimuli-Mpungu E, Wamala K, Okello J, Alderman S, Odokonyero R, Mojtabai R, et al. Group support psychotherapy for depression treatment in people with HIV/AIDS in northern Uganda: a single-centre randomised controlled trial. The Lancet HIV 2015 May;2(5):e190-e199. [doi: 10.1016/S2352-3018(15)00041-7]

22. Roberts B, Ocaka KF, Browne J, Oyok T, Sondorp E. Factors associated with post-traumatic stress disorder and depression amongst internally displaced persons in northern Uganda. BMC Psychiatry 2008 May 19;8:38 [FREE Full text] [doi: 10.1186/1471-244X-8-38] [Medline: 18489768]

23. Nakimuli-Mpungu E, Musisi S, Wamala K, Okello J, Ndyanabangi S, Mojtabai R, et al. The effect of group support psychotherapy delivered by trained lay health workers for depression treatment among people with HIV in Uganda: protocol of a pragmatic, cluster randomized trial. JMIR Res Protoc 2017 Dec 11;6(12):e250 [FREE Full text] [doi: 10.2196/resprot.8925] [Medline: 29229589]

24. Nakimuli-Mpungu E, Wamala K, Okello J, Ndyanabangi S, Kanters S, Mojtabai R, et al. Process evaluation of a randomized controlled trial of group support psychotherapy for depression treatment among people with HIV/AIDS in Northern Uganda. 
Community Ment Health J 2017 Dec;53(8):991-1004 [FREE Full text] [doi: 10.1007/s10597-017-0129-4] [Medline: 28317086]

25. Baingana F, Mangen PO. Scaling up of mental health and trauma support among war affected communities in northern Uganda. Intervention 2011:1. [doi: 10.1097/WTF.0b013e32834dfcc3]

26. Sheehan DV, Lecrubier Y, Sheehan KH, Amorim P, Janavs J, Weiller E, et al. The Mini-International Neuropsychiatric Interview (M.I.N.I.): the development and validation of a structured diagnostic psychiatric interview for DSM-IV and ICD-10. J Clin Psychiatry 1998;59 Suppl 20:22-33;quiz 34 [FREE Full text] [Medline: 9881538]

27. Patterson WM, Dohn HH, Bird J, Patterson GA. Evaluation of suicidal patients: The SAD PERSONS scale. Psychosomatics 1983 Apr;24(4):343-349. [doi: 10.1016/S0033-3182(83)73213-5]

28. Muhwezi WW, Okello ES, Neema S, Musisi S. Caregivers' experiences with major depression concealed by physical illness in patients recruited from central Ugandan Primary Health Care Centers. Qual Health Res 2008 Aug;18(8):1096-1114. [doi: 10.1177/1049732308320038] [Medline: 18650565]

29. Beusenberg M, Orley J, World Health Organization. A User's Guide to the Self-Reporting Questionnaire (SRQ). Geneva: World Health Organization; 1994.

30. Nakimuli-Mpungu E, Mojtabai R, Alexandre PK, Katabira E, Musisi S, Nachega JB, et al. Cross-cultural adaptation and validation of the self-reporting questionnaire among HIV+ individuals in a rural ART program in southern Uganda. HIV AIDS (Auckl) 2012;4:51-60 [FREE Full text] [doi: 10.2147/HIV.S29818] [Medline: 22570575]

31. Nakimuli-Mpungu E, Alderman S, Kinyanda E, Allden K, Betancourt TS, Alderman JS, et al. Implementation and scale-up of psycho-trauma centers in a post-conflict area: a case study of a private-public partnership in northern Uganda. PLoS Med 2013;10(4):e1001427 [FREE Full text] [doi: 10.1371/journal.pmed.1001427] [Medline: 23610562]

32. Mollica R. Harvard Program in Refugee Trauma. 2004. Measuring trauma, measuring torture URL: http://hprt-cambridge. org/screening/measuring-trauma-measuring-torture/ [accessed 2018-12-06] [WebCite Cache ID 74TEwNn7r]

33. Zimet GD, Dahlem NW, Zimet SG, Farley GK. The Multidimensional Scale of Perceived Social Support. J Pers Assess 1988 Mar;52(1):30-41. [doi: 10.1207/s15327752jpa5201 2]

34. Nakigudde J, Musisi S, Ehnvall A, Airaksinen E, Agren H. Adaptation of the multidimensional scale of perceived social support in a Ugandan setting. Afr Health Sci 2009 Aug 01;9 Suppl 1:S35-S41 [FREE Full text] [Medline: 20589159]

35. Rosenberg M. Society and the Adolescent Self-Image. Princeton, NJ: Princeton University Press; 1965.

36. Mundell JP, Visser MJ, Makin JD, Kershaw TS, Forsyth BW, Jeffery B, et al. The impact of structured support groups for pregnant South African women recently diagnosed HIV positive. Women Health 2011 Aug 31;51(6):546-565 [FREE Full text] [doi: 10.1080/03630242.2011.606356] [Medline: 21973110]

37. Nakamura A, Osonoi T, Terauchi Y. Relationship between urinary sodium excretion and pioglitazone-induced edema. J Diabetes Investig 2010 Oct 19;1(5):208-211 [FREE Full text] [doi: 10.1111/j.2040-1124.2010.00046.x] [Medline: 24843434]

38. Carver C, Scheier M, Weintraub J. Assessing coping strategies: a theoretically based approach. J Pers Soc Psychol 1989 Feb;56(2):267-283. [Medline: 2926629]

39. Kalichman SC, Simbayi LC, Jooste S, Toefy Y, Cain D, Cherry C, et al. Development of a brief scale to measure AIDS-related stigma in South Africa. AIDS Behav 2005 Jun;9(2):135-143. [doi: 10.1007/s10461-005-3895-x] [Medline: 15933833]

40. Nyblade L, MacQuarrie K. Can We Measure HIV/AIDS-Related Stigma and Discrimination? Current Knowledge About Quantifying Stigma in Developing Countries. Washington: US Agency for International Development; 2017. URL: https:/ /pdf.usaid.gov/pdf docs/ [accessed 2018-12-07] [WebCite Cache ID 74UDcrepA]

41. Liu H, Golin CE, Miller LG, Hays RD, Beck CK, Sanandaji S, et al. A comparison study of multiple measures of adherence to HIV protease inhibitors. Ann Intern Med 2001 May 15;134(10):968-977. [Medline: 11352698]

42. Golin CE, Liu H, Hays RD, Miller LG, Beck CK, Ickovics J, et al. A prospective study of predictors of adherence to combination antiretroviral medication. J Gen Intern Med 2002 Oct;17(10):756-765 [FREE Full text] [Medline: 12390551]

43. Petersen I, Hanass Hancock J, Bhana A, Govender K. A group-based counselling intervention for depression comorbid with HIV/AIDS using a task shifting approach in South Africa: a randomized controlled pilot study. J Affect Disord 2014 Apr;158:78-84. [doi: 10.1016/j.jad.2014.02.013] [Medline: 24655769]

44. Kaaya SF, Blander J, Antelman G, Cyprian F, Emmons KM, Matsumoto K, et al. Randomized controlled trial evaluating the effect of an interactive group counseling intervention for HIV-positive women on prenatal depression and disclosure of HIV status. AIDS Care 2013;25(7):854-862. [doi: 10.1080/09540121.2013.763891] [Medline: 23383726]

45. Chibanda D, Weiss HA, Verhey R, Simms V, Munjoma R, Rusakaniko S, et al. Effect of a primary care-based psychological intervention on symptoms of common mental disorders in Zimbabwe: a randomized clinical trial. JAMA 2016 Dec 27;316(24):2618-2626. [doi: 10.1001/jama.2016.19102] [Medline: 28027368]

46. Bolton P, Bass J, Neugebauer R, Verdeli H, Clougherty KF, Wickramaratne P, et al. Group interpersonal psychotherapy for depression in rural Uganda: a randomized controlled trial. JAMA 2003 Jun 18;289(23):3117-3124. [doi: 10.1001/jama.289.23.3117] [Medline: 12813117]

47. Buvé A, Bishikwabo-Nsarhaza K, Mutangadura G. The spread and effect of HIV-1 infection in sub-Saharan Africa. Lancet 2002 Jun 08;359(9322):2011-2017. [doi: 10.1016/S0140-6736(02)08823-2] [Medline: 12076570]

48. Wojcicki JM. Socioeconomic status as a risk factor for HIV infection in women in East, Central and Southern Africa: a systematic review. J Biosoc Sci 2005 Jan;37(1):1-36. [Medline: 15688569] 
49. Lund C, Breen A, Flisher AJ, Kakuma R, Corrigall J, Joska JA, et al. Poverty and common mental disorders in low and middle income countries: a systematic review. Soc Sci Med 2010 Aug;71(3):517-528 [FREE Full text] [doi: 10.1016/j.socscimed.2010.04.027] [Medline: 20621748]

50. Richardson R, Westley T, Gariépy G, Austin N, Nandi A. Neighborhood socioeconomic conditions and depression: a systematic review and meta-analysis. Soc Psychiatry Psychiatr Epidemiol 2015 Nov;50(11):1641-1656. [doi: 10.1007/s00127-015-1092-4] [Medline: 26164028]

51. Bonfils KA, Lysaker PH, Yanos PT, Siegel A, Leonhardt BL, James AV, et al. Self-stigma in PTSD: prevalence and correlates. Psychiatry Res 2018 Jul;265:7-12 [FREE Full text] [doi: 10.1016/j.psychres.2018.04.004] [Medline: 29679793]

52. Greene T, Neria Y, Gross R. Prevalence, detection and correlates of PTSD in the primary care setting: a systematic review. J Clin Psychol Med Settings 2016 Dec;23(2):160-180. [doi: 10.1007/s10880-016-9449-8] [Medline: 26868222]

53. Hernandez D, Kalichman SC, Katner HP, Burnham K, Kalichman MO, Hill M. Psychosocial complications of HIV/AIDS-metabolic disorder comorbidities among patients in a rural area of southeastern United States. J Behav Med 2018 Aug;41(4):441-449 [FREE Full text] [doi: 10.1007/s10865-018-9912-0] [Medline: 29383534]

54. Rock PL, Roiser JP, Riedel WJ, Blackwell AD. Cognitive impairment in depression: a systematic review and meta-analysis. Psychol Med 2014 Jul;44(10):2029-2040. [doi: 10.1017/S0033291713002535] [Medline: 24168753]

55. Fried EI, Nesse RM. The impact of individual depressive symptoms on impairment of psychosocial functioning. PLoS One 2014;9(2):e90311 [FREE Full text] [doi: 10.1371/journal.pone.0090311] [Medline: 24587318]

56. Cobb S. Presidential address-1976: social support as a moderator of life stress. Psychosom Med 1976;38(5):300-314. [Medline: 981490]

57. Cohen S, Wills TA. Stress, social support, and the buffering hypothesis. Psychol Bull 1985 Sep;98(2):310-357. [Medline: 3901065]

58. Stein ER, Smith BW. Social support attenuates the harmful effects of stress in healthy adult women. Soc Sci Med 2015 Dec;146:129-136. [doi: 10.1016/j.socscimed.2015.10.038] [Medline: 26513122]

59. Uthman OA, Magidson JF, Safren SA, Nachega JB. Depression and adherence to antiretroviral therapy in low-, middleand high-income countries: a systematic review and meta-analysis. Curr HIV/AIDS Rep 2014 Sep;11(3):291-307 [FREE Full text] [doi: 10.1007/s11904-014-0220-1] [Medline: $\underline{\text { 25038748] }}$

60. Mugavero MJ, Pence BW, Whetten K, Leserman J, Swartz M, Stangl D, et al. Predictors of AIDS-related morbidity and mortality in a southern US cohort. AIDS Patient Care STDS 2007 Sep;21(9):681-690. [doi: 10.1089/apc.2006.0167] [Medline: 17919095]

61. Ironson G, O'Cleirigh C, Fletcher MA, Laurenceau JP, Balbin E, Klimas N, et al. Psychosocial factors predict CD4 and viral load change in men and women with human immunodeficiency virus in the era of highly active antiretroviral treatment. Psychosom Med 2005;67(6):1013-10121 [FREE Full text] [doi: 10.1097/01.psy.0000188569.58998.c8] [Medline: 16314608]

62. Ammassari A, Trotta MP, Murri R, Castelli F, Narciso P, Noto P, AdICoNA Study Group. Correlates and predictors of adherence to highly active antiretroviral therapy: overview of published literature. J Acquir Immune Defic Syndr 2002 Dec 15;31 Suppl 3:S123-S127. [Medline: 12562034]

\section{Abbreviations}

ART: antiretroviral therapy

AUDIT: Alcohol Use Disorders Identification Test

GSP: group support psychotherapy

LHW: lay health worker

MINI: Mini International Neuropsychiatric Interview

PLWH: person living with HIV

SEEK-GSP: Social, Emotional, and Economic Empowerment Through Knowledge of Group Support Psychotherapy

WHO: World Health Organization 
Edited by N Kuter; submitted 13.07.18; peer-reviewed by KP Wong, M Noll-Hussong; comments to author 31.08.18; revised version received 25.10.18; accepted 01.11.18; published 03.01.19

Please cite as:

Nakimuli-Mpungu E, Musisi S, Wamala K, Okello J, Ndyanabangi S, Birungi J, Nanfuka M, Etukoit M, Mojtabai R, Nachega J, Harari $O$, Mills $E$

Recruitment and Baseline Characteristics of Participants in the Social, Emotional, and Economic Empowerment Through Knowledge of Group Support Psychotherapy Study (SEEK-GSP): Cluster Randomized Controlled Trial

JMIR Res Protoc 2019;8(1):e11560

URL: http://www.researchprotocols.org/2019/1/e11560/

doi: $\underline{10.2196 / 11560}$

PMID: 30609989

(CEtheldreda Nakimuli-Mpungu, Seggane Musisi, Kizito Wamala, James Okello, Sheila Ndyanabangi, Josephine Birungi, Mastula Nanfuka, Michael Etukoit, Ramin Mojtabai, Jean Nachega, Ofir Harari, Edward Mills. Originally published in JMIR Research Protocols (http://www.researchprotocols.org), 03.01.2019. This is an open-access article distributed under the terms of the Creative Commons Attribution License (https://creativecommons.org/licenses/by/4.0/), which permits unrestricted use, distribution, and reproduction in any medium, provided the original work, first published in JMIR Research Protocols, is properly cited. The complete bibliographic information, a link to the original publication on http://www.researchprotocols.org, as well as this copyright and license information must be included. 